\title{
Produção científica sobre análise de desempenho técnico-tático no futsal
}

\author{
Scientific production on technical and tactical performance analysis in futsal \\ Producción científica sobre el análisis del rendimiento técnico y táctico en el fútbol sala
}

\author{
Mylena Aparecida Rodrigues Alves \\ ORCID: https://orcid.org/0000-0001-8614-407X \\ Universidade Federal do Paraná, Brasil \\ E-mail: mylena_cg@hotmail.com \\ Daniel Cavalcante da Graça \\ ORCID https://orcid.org/0000-0002-7155-7493 \\ Escola de Engenharia Mauá, Brasi \\ E-mail: daniel.cgraca@gmail.com \\ Miquéias Correia Feitosa \\ ORCID https://orcid.org/0000-0001-8274-1213 \\ Faculdade Estácio de Alagoas, Brasil \\ E-mail: miqueiascorreia.f@gmail.com \\ Bem Hur Soares \\ ORCID https://orcid.org/0000-0001-6762-4799 \\ Universidade de Passo Fundo, Brasil \\ E-mail: benhur@upf.br
}

\begin{abstract}
Resumo
O presente estudo de revisão procurou compilar informações disponibilizadas na literatura quanto aos estudos da análise de desempenho no futsal com a finalidade de traçar a realidade que a produção científica se encontra sobre a análise de desempenho no futsal. Para tal, a busca de publicações acadêmicas foi realizada nas bases de dados EBSCO (SportDiscus), PubMed, Web of Science, SciElo, Scopus, BVS e EMBASE com os seguintes descritores: análise de desempenho, análise notacional, análise de jogo, análise tática, padrão de jogo, futsal e futebol de salão, nos idiomas inglês, espanhol e português. Foram selecionados 50 artigos conforme os critérios de inclusão e exclusão estabelecidos. Retornou 238 ações analisadas em jogadores e jogos no futsal, sendo que as mais analisadas foram o passe, chute e gol. A sua distribuição ficou da seguinte maneira, conforme seus atributos estabelecidos: técnico $(65,97 \%)$, tático $(19,75 \%)$, do goleiro $(8,40 \%)$ e bolas paradas $(5,88 \%)$. Dessa forma, os atributos técnicos são os de maior interesse entre os pesquisadores da área. Recomenda-se mais estudos direcionados ao futsal feminino, goleiros e em ações defensivas (desarmes, roubada de bola e interceptações). O futuro da análise de desempenho no futsal é tratado.
\end{abstract}

Palavras-chave: Futsal; Análise de desempenho; Análise de jogo; Produção científica.

\begin{abstract}
The present review study sought to compile information available in the literature regarding the studies of performance analysis in futsal with the purpose of tracing the reality that the scientific production is about the performance analysis in futsal. To this end, the search for academic publications was conducted in the EBSCO (SportDiscus), PubMed, Web of Science, SciElo, Scopus, BVS and EMBASE databases with the following descriptors: performance analysis, notational analysis, game analysis, tactical analysis, game pattern, futsal and indoor soccer, in English, Spanish and Portuguese. Fifty articles were selected according to the established inclusion and exclusion criteria. It returned 238 actions analyzed in players and games in futsal, and the most analyzed were the pass, kick and goal. They were distributed as follows, according to their attributes: technical (65.97\%), tactical $(19.75 \%)$, goalkeeper $(8.40 \%)$ and set pieces $(5.88 \%)$. Thus, the technical attributes are the ones of greatest interest among researchers in the area. We recommend more studies directed at women's futsal, goalkeepers, and defensive actions (tackles, steal of the ball, and interceptions). The future of performance analysis in futsal is addressed.
\end{abstract}

Keywords: Futsal; Performance analysis; Match analysis; Scientific production.

\section{Resumen}

El presente estudio de revisión buscó recopilar la información disponible en la literatura sobre los estudios de análisis del rendimiento en el fútbol sala con el propósito de rastrear la realidad que la producción científica tiene sobre el análisis del rendimiento en el fútbol sala. Para ello, se realizó la búsqueda de publicaciones académicas en las bases de datos EBSCO (SportDiscus), PubMed, Web of Science, SciElo, Scopus, BVS y EMBASE con los siguientes descriptores: performance analysis, notational analysis, game analysis, tactical analysis, game pattern, futsal and 
indoor football, en los idiomas inglés, español y portugués. Se seleccionaron 50 artículos según los criterios de inclusión y exclusión establecidos. Regresaron 238 acciones analizadas en jugadores y partidos de fútbol sala, y las más analizadas fueron el pase, la patada y el gol. Su distribución fue la siguiente, según sus atributos establecidos: técnica $(65,97 \%)$, táctica $(19,75 \%)$, portería $(8,40 \%)$ y balones parados $(5,88 \%)$. De este modo, los atributos técnicos son los de mayor interés entre los investigadores del área. Se recomiendan más estudios dirigidos al fútbol sala femenino, a las porteras y en las acciones defensivas (entradas, robos de balón e intercepciones). Se aborda el futuro del análisis del rendimiento en el fútbol sala.

Palabras clave: Fútbol sala; Análisis del rendimiento; Análisis del juego; Producción científica.

\section{Introdução}

A análise de desempenho no esporte vem auxiliando treinadores, atletas e pesquisadores a desenvolverem uma compreensão objetiva do desempenho esportivo de forma real. No esporte de alto rendimento a análise de desempenho tem se mostrado uma técnica indispensável em diversas equipes esportivas, permitindo aos atletas e treinadores obterem feedbacks em tempo real de estatísticas de partidas e sequências de vídeo usando sistemas ajustáveis de internet. O comportamento de um atleta em competição esportiva é o produto de muitos processos complexos (Junior, 2002), a ciência do esporte tem como objetivo de compreender estes processos em um nível fundamental e, a análise de desempenho pode contribuir em sanar diversas questões sobre o comportamento de equipes e atletas.

A natureza dinâmica e imprescindível do jogo de futsal proporciona infinitas maneiras para coletar os dados, em que os analistas são impossibilitados de observarem a totalidade das ações no decorrer de um jogo. No sentido de minimizar essa limitação, as observações e as ferramentas que auxiliam na coleta, permitem uma melhor descrição das ações do jogo dentro do âmbito físico, técnico, tático e psicológico (Carling, Reilly \& Willians, 2008). Por meio dessas observações procura-se uma melhor realidade do objeto ao que se pretendo conhecer (Contreras \& Pino, 200).

Segundo Bacconi e Marella (1995), convém afirmar que existem tantos métodos e processos para analisar um jogo quanto as suas interpretações. De acordo com Hughes e Bartlett (2008) e Barreira (2013) existem cinco principais formas de utilizar a análise de jogo: 1) Análise tática: refere-se as interações comportamentais que tentam explicar os pontos fortes e fracos num jogo; 2) Análise técnica: seleciona as ações técnicas, pré-determinadas e às respectivas eficiência e eficácia; 3) Análise do movimento: identificação dos indicadores fisiológicos e biomecânicos, trabalho produzido e o gasto energético dos jogadores; 4) Desenvolvimento de bases e modelação: reconhecimento dos parâmetros do desempenho esportivo (físico, técnico, tático e psicológico) com o intuito de predizer a evolução do desempenho, seja no treino ou em competição; 5) Formação de treinadores e de jogadores: aplicação do conhecimento adquirido do jogo para o desenvolvimento de treinadores e jogadores. 
Figura 1. Cinco formas que a análise de jogo pode ser inserida no contexto esportivo.

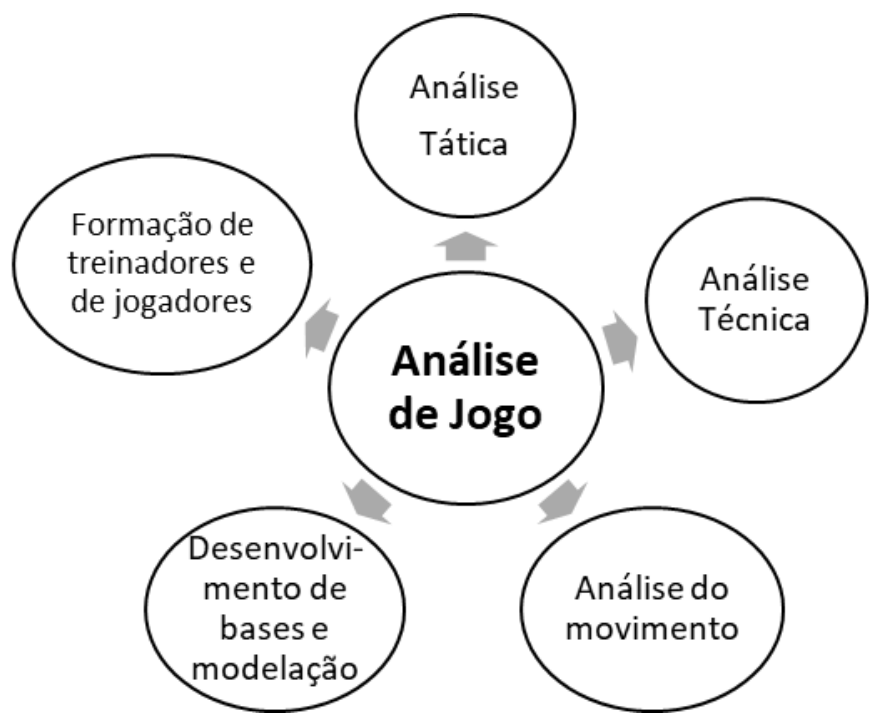

Fonte: adaptado de Hughes e Bartlett (2008).

Quanto à abordagem dos métodos de análises, Godik e Popov (1993) afirmam que para obter um conhecimento profundo e minucioso das técnicas e táticas coletivas, os observadores necessitam requerer procedimentos de análise quantitativos e qualitativos, pois apenas com a complementação de ambos os métodos que se obterá informações completas e mais confiáveis. Assim, a abordagem mista tem o potencial para produzir um entendimento mais robusto dos fenómenos complexos do jogo se comparado aos métodos isolados (Heyvaert \& Onghena, 2013).

Como já tratado, a análise de desempenho vem auxiliando nas tomadas de decisões em equipes competitivas, porém ainda se tem muito a ser investigada, devido a sua ampla inserção e evolução no ambiente esportivo.

Nesse contexto, o presente manuscrito tem como objetivo mapear o que se tem produzido cientificamente sobre a análise de desempenho no futsal. Propõe-se apresentar algumas particularidades da literatura científica, identificando as seguintes variáveis: sexo, participantes, nível das equipes analisadas, fator analisado, título do periódico de publicação, ano de publicação, ações analisadas, os autores, principal objetivo e principais achados de cada estudo selecionado. A partir destas descrições, visa-se traçar a realidade que a produção cientifica se encontra sobre a análise de desempenho no futsal.

\section{Materiais e Métodos}

A presente pesquisa foi classificada como uma revisão integrativa, pois esse método tem o potencial de permitir que diversos métodos de pesquisa primária se tornem uma parte maior sobre determinado assunto (Whittemore \& Knafl, 2005).

A busca foi realizada no dia 20 de julho de 2020, não se tendo delimitado o ano inicial de publicação. De forma a limitar o universo explorado pela presente investigação, foi utilizado uma estratégia de busca nos seguintes bancos de dados eletrônicos: SPORTDiscus na área da Educação Física; BVS (Biblioteca Virtual em Saúde), Web of Science, Scopus, PubMed, Scielo (Scientific Electronic Library Online) e EMBASE, na área das Ciências da Saúde. Com os seguintes descritores: análise de jogo, análise de desempenho, análise notacional, análise tática, padrão de jogo, futsal e futebol de salão, combinados pelo operador booleano AND e OR e o símbolo entre aspas (“") para palavras compostas. Nos idiomas inglês, espanhol e português.

A equação de busca dos três idiomas foram as seguintes: inglês [("match analysis" OR "performance analysis" OR "notational analysis" OR "game analysis" OR "tactical analysis" OR "patterns of play") AND (futsal OR "indoor soccer")]; 
espanhol ("análisis de partido" OR "análisis de rendimiento" OR "análisis de notación" OR "análisis de juego" OR "análisis táctico" OR "patrones de juego") AND (futsal OR "futbol sala"); português ("análise de desempenho" OR "análise notacional" OR "análise de jogo" OR "análise tática" OR "padr* de jogo") AND (futsal OR "futebol de salão").

\section{Critérios de elegibilidade}

Como critérios de inclusão, estabeleceu-se: 1) artigos científicos publicados em periódicos; 2) dentro do contexto esportivo; 3) jogadores de futsal; 4) encontrado na íntegra; 5) na metodologia houve a análise de ações técnicas ou táticas individuais ou coletivas. Consideram-se como critérios de exclusão revisões, artigos de construção e/ou validação de ferramenta, livros, capítulos de livros e resumos de congressos. Dois revisores independentes selecionaram de forma imparcial estudos para identificar artigos científicos que potencialmente atendessem aos critérios de inclusão, quando necessário, as divergências foram resolvidas com participação de um terceiro autor, no intuito de se chegar a um consenso. Desta forma, todas as decisões finais resultaram de um processo de tomada de decisão conjunta.

Foi organizado os resultados em uma planilha do Microsoft Office Excel® para uma análise posterior. A estatística descritiva, com base nas frequências absolutas e relativas, foi utilizada no banco de dados coletados quando necessário.

Dos 216 artigos encontrados, 50 artigos atenderam aos critérios de inclusão, separado em etapas de leitura (título, resumo e íntegra). A Figura 2 apresenta o passo a passo seguido na seleção dos artigos analisados no presente estudo.

Figura 2. Etapas da busca

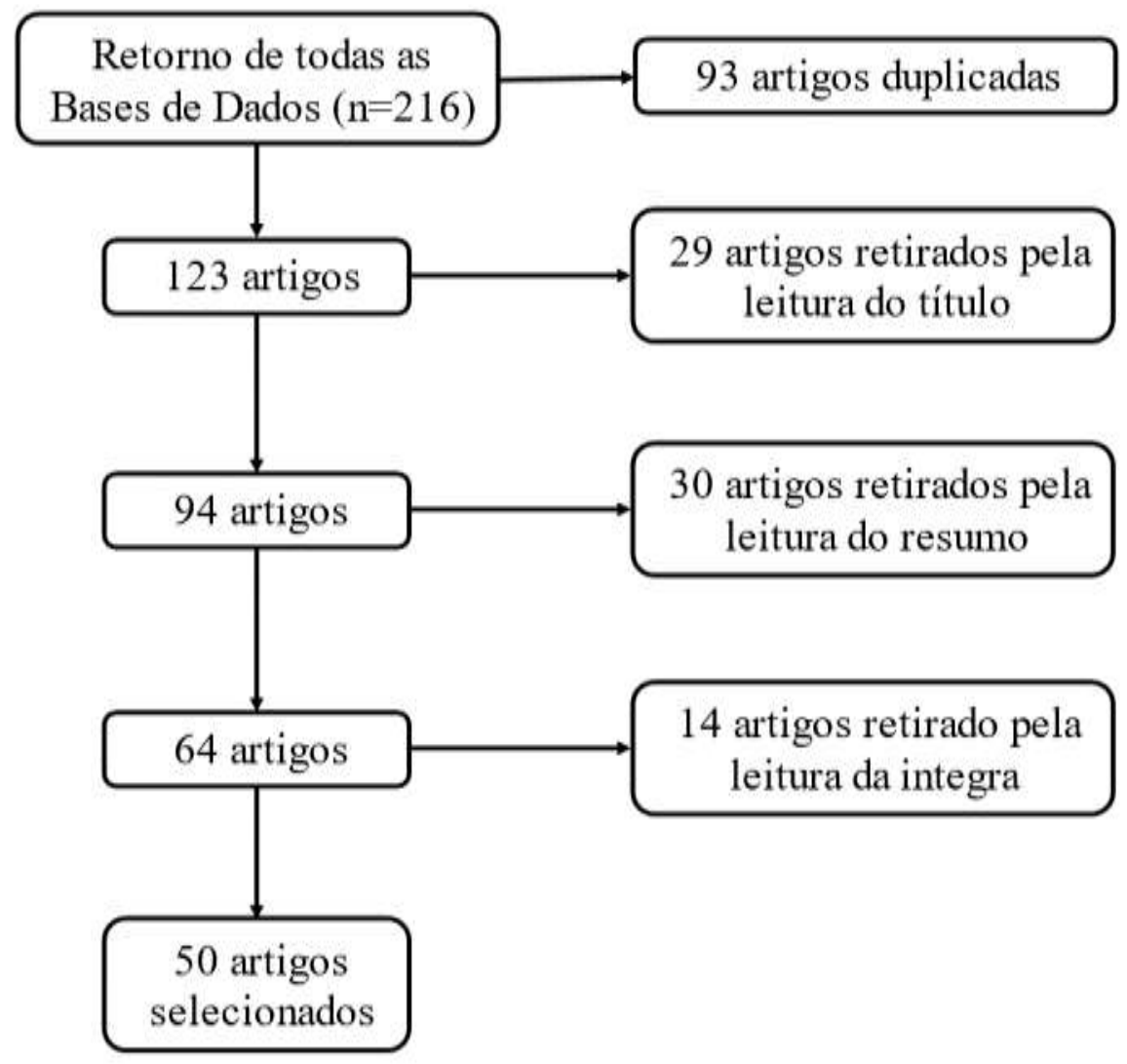

Fonte: Autores (2021).

\section{Resultados e Discussão}

O retorno inicial foi de 216 artigos científicos, após aplicação dos critérios de inclusão e exclusão, o retorno passou 
para 50, onde foram selecionados para contemplar a presente revisão. Os 50 artigos selecionados são descritos no Quadro 1.

Quadro 1. Características dos estudos selecionados.

\begin{tabular}{|c|c|c|c|}
\hline ID & Citação & Principal Objetivo & Principais achados \\
\hline 1 & $\begin{array}{l}\text { Amaral e } \\
\text { Garganta } \\
(2005)\end{array}$ & $\begin{array}{l}\text { (i) identificar as acções táctico-técnicas que são } \\
\text { induzidas (activadas) pelo 1x1, e as que são } \\
\text { indutoras (activadoras) da referida situação; (ii) } \\
\text { descrever as características das situações de } 1 \times 1 \\
\text { que mais frequentemente provocam o } \\
\text { desequilíbrio defensivo do adversário; (iii) } \\
\text { fornece algumas orientações práticas para o } \\
\text { treino do } 1 \times 1 \text {. }\end{array}$ & $\begin{array}{c}\text { O drible de progressão e o drible para remate são os } \\
\text { tipos de } 1 \text { x } 1 \text { que mais provocam o desequilíbrio } \\
\text { defensivo do adversário; ao nível do contexto de } \\
\text { cooperação, o 1x1 com vários apoios é aquele que } \\
\text { apresenta maior probabilidade de conduzir a uma } \\
\text { situação de } \\
\text { remate }\end{array}$ \\
\hline 2 & $\begin{array}{l}\text { Aburachid et } \\
\text { al. (2010) }\end{array}$ & $\begin{array}{c}\text { Caracterizar o perfil das ações em diferentes } \\
\text { categorias. }\end{array}$ & $\begin{array}{c}\text { Os dados apresentaram uma predominância da } \\
\text { origem dos contra-ataques na meia-quadra } \\
\text { defensiva, com desenvolvimento por ações táticas } \\
\text { de grupo. O erro de passe do adversário } \\
\text { predominou como ação indutora do contra-ataque } \\
\text { nas categorias adulto profissional e sub-17 e na } \\
\text { categoria adulto o desarme foi prioritariamente } \\
\text { utilizado. }\end{array}$ \\
\hline 3 & $\begin{array}{l}\text { Jovanovic, } \\
\text { Sporis e } \\
\text { Milanovic } \\
\quad(2011)\end{array}$ & $\begin{array}{l}\text { Determinar similaridade em parâmetros } \\
\text { morfológicos e situacionais entre futsal e } \\
\text { futebol }\end{array}$ & $\begin{array}{l}\text { Os resultados deste estudo mostraram que os } \\
\text { jogadores de futsal e de futebol diferem apenas em } \\
\text { dois parâmetros situacionais (posse da bola e } \\
\text { corrida com a bola) }\end{array}$ \\
\hline 4 & $\begin{array}{l}\text { Santana e } \\
\text { Vacario } \\
(2012)\end{array}$ & - & $\begin{array}{l}\text { Concluiu-se que é preciso aumentar a eficácia em } \\
\text { faltas com barreira, sobre tudo em zonas laterais }\end{array}$ \\
\hline 5 & $\begin{array}{l}\text { Vilar et al. } \\
\text { (2012b) }\end{array}$ & $\begin{array}{c}\text { Explica como os jogadores coordenam suas } \\
\text { ações para criar/prevenir oportunidades de } \\
\text { marcar gols }\end{array}$ & $\begin{array}{l}\text { Este estudo identificou padrões emergentes de } \\
\text { coordenação entre atacantes e defensores sob } \\
\text { restrições de tarefas competitivas chave, tais como a } \\
\text { localização do gol, o que apoiou o desempenho } \\
\text { bem-sucedido no futsal. }\end{array}$ \\
\hline 6 & $\begin{array}{l}\text { Travassos et } \\
\text { al. (2012) }\end{array}$ & $\begin{array}{c}\text { Investigar os efeitos da manipulação do número } \\
\text { de possibilidades de ação em uma tarefa } \\
\text { passageira futsal para compreender a } \\
\text { representatividade dos projetos de tarefas } \\
\text { práticas. }\end{array}$ & $\begin{array}{c}\text { A regularidade da velocidade da bola provou ser um } \\
\text { descritor confiável que pode ser usado para avaliar } \\
\text { a representatividade das tarefas de prática de passes } \\
\text { em esportes coletivos }\end{array}$ \\
\hline 7 & $\begin{array}{l}\text { Vilar et al. } \\
\text { (2012b) }\end{array}$ & $\begin{array}{c}\text { Examinar a influência dos jogadores } \\
\text { adversários que restringem a tomada de decisão } \\
\text { de um atacante durante o desempenho do chute } \\
\text { no futsal }\end{array}$ & $\begin{array}{c}\text { Os resultados mostraram que os valores de distância } \\
\text { de um defensor e goleiro até os pontos de } \\
\text { interceptação eram significativamente menores } \\
\text { quando interceptavam a bola. }\end{array}$ \\
\hline 8 & $\begin{array}{l}\text { Ribeiro et al. } \\
\text { (2013) }\end{array}$ & $\begin{array}{l}\text { Caracterizar os indicadores de rendimento em } \\
\text { jogos de futsal, a partir da análise de aspectos } \\
\text { técnico-táticos das situações de finalização }\end{array}$ & $\begin{array}{l}\text { Verificou-se, assim, que as melhores equipes } \\
\text { finalizaram mais e com um percentual maior nas } \\
\text { situações de jogo organizado. }\end{array}$ \\
\hline 9 & $\begin{array}{l}\text { Lapresa et al. } \\
\text { (2013) }\end{array}$ & $\begin{array}{l}\text { Analisar a fase ofensiva da seleção nacional que } \\
\text { venceu o Campeonato da UEFA de } 2010 \text {. }\end{array}$ & $\begin{array}{l}\text { Os padrões temporais obtidos - além de elaborar } \\
\text { sobre a relação entre a área de onde o tiro é feito, a } \\
\text { superfície de contato utilizada e o tipo de tiro - } \\
\text { permitem uma interpretação tática das ações } \\
\text { técnicas que suportam o desenvolvimento da fase } \\
\text { ofensiva do futsal. }\end{array}$ \\
\hline 10 & $\begin{array}{l}\text { Muller, Costa } \\
\text { e Garganta } \\
\quad(2013)\end{array}$ & $\begin{array}{l}\text { Comparar comportamentos táticos de jogadores } \\
\text { de futsal das } \\
\text { categorias sub-13, sub-15, sub-17 e sub-20 }\end{array}$ & $\begin{array}{l}\text { Constata-se que os jogadores da categoria sub-20 } \\
\text { erraram menos na "fase defensiva" e no "jogo" e } \\
\text { obtiveram melhores índices de performance tática } \\
\text { na "fase defensiva" comparados com os jogadores } \\
\text { das categorias sub-15 e sub-17. }\end{array}$ \\
\hline 11 & $\begin{array}{l}\text { Alvurdu } \\
(2013)\end{array}$ & $\begin{array}{l}\text { Analisar os aspectos técnicos e táticos da } \\
\text { Seleção Turca de Futsal (TFNT) que participou } \\
\text { no UEFA Futsal EURO } 2012 \text { pela primeira vez. }\end{array}$ & $\begin{array}{c}\text { Esta análise permitiu concluir que a qualificação } \\
\text { técnica e tática do TFNT permaneceu } \\
\text { consideravelmente baixa em comparação com as } \\
\text { equipes adversárias. }\end{array}$ \\
\hline
\end{tabular}




\begin{tabular}{|c|c|c|c|}
\hline 12 & $\begin{array}{l}\text { Campos } \\
(2014)\end{array}$ & $\begin{array}{l}\text { Analisar como ocorreram os gols em jogos no } \\
\text { campeonato estadual de futsal de São Paulo de } \\
2012\end{array}$ & $\begin{array}{c}\text { Pode-se concluir que há uma vantagem em gols no } \\
\text { contexto técnico-tático de Jogadas Combinadas e as } \\
\text { jogadas de bola parada também foram significativas } \\
\text { na pesquisa }\end{array}$ \\
\hline 13 & $\begin{array}{l}\text { Miloski et al. } \\
\qquad(2014)\end{array}$ & $\begin{array}{l}\text { O objetivo do presente estudo foi verificar se as } \\
\text { ações técnico-táticas específicas do futsal são } \\
\text { capazes de discriminar o resultado de partidas } \\
\text { de uma equipe de alto rendimento. }\end{array}$ & $\begin{array}{l}\text { Os resultados do presente estudo permitem concluir } \\
\text { que a eficiência em relação ao número de Desarmes } \\
\text { Realizados e de Desarmes Sofridos pode ser um } \\
\text { fator importante para resultado de vitória em } \\
\text { partidas de futsal de alto rendimento. Assim, este } \\
\text { estudo aponta que as ações técnico-táticas de } \\
\text { desarme referentes ao sistema defensivo de } \\
\text { determinada equipe de futsal podem discriminar o } \\
\text { resultado da partida, bem como para a importância } \\
\text { do sistema ofensivo no que diz respeito a uma } \\
\text { melhor organização do ataque e, consequentemente, } \\
\text { uma menor possibilidade de sofrer desarmes }\end{array}$ \\
\hline 14 & $\begin{array}{l}\text { Doğramac et } \\
\text { al. (2015a) }\end{array}$ & $\begin{array}{c}\text { O estudo também objetivou detectar o } \\
\text { desempenho indicadores que diferiam entre as } \\
\text { equipes, tais como posse de bola e sucesso de } \\
\text { tiro }\end{array}$ & $\begin{array}{l}\text { Estes resultados geralmente sugerem que a menor } \\
\text { atividade de alta intensidade e a maior posse de } \\
\text { bola e precisão de passe parecem ser determinantes } \\
\text { críticos na discriminação entre desempenho de jogo } \\
\text { bem-sucedido e malsucedido. }\end{array}$ \\
\hline 15 & $\begin{array}{l}\text { Schneider et } \\
\text { al. (2015) }\end{array}$ & $\begin{array}{l}\text { Analisar os períodos de maior ocorrência de } \\
\text { gols sofridos e gols feitos pela equipe de futsal } \\
\text { de Nova Itaberaba/SC da categoria sub-17 no } \\
\text { campeonato catarinense } 2013 / 2014\end{array}$ & $\begin{array}{l}\text { A maioria dos gols feitos ocorreu no } 3^{\circ} \text { período e os } \\
\text { gols sofridos ocorreram no } 4^{\circ} \text { período, } \\
\text { corroborando com a maioria das pesquisas nesta } \\
\text { temática }\end{array}$ \\
\hline 16 & $\begin{array}{l}\text { Doğramac et } \\
\text { al. }(2015 b)\end{array}$ & $\begin{array}{c}\text { Quantificar o perfil das atividades em jogadores } \\
\text { de futsal durante um torneio e, detectar } \\
\text { mudanças no desempenho. }\end{array}$ & $\begin{array}{c}\text { Uma diminuição no sprint e um aumento na } \\
\text { caminhada foi evidenciado para o início ao final do } \\
\text { torneio, sugere um acúmulo de fadiga. } \\
\text { Interessantemente, essas mudanças não aparecem } \\
\text { influenciar o desempenho. }\end{array}$ \\
\hline 17 & $\begin{array}{l}\text { Gómez et al. } \\
\text { (2015) }\end{array}$ & $\begin{array}{l}\text { O objetivo do presente estudo foi identificar a } \\
\text { importância da eficácia da posse de bola no } \\
\text { futsal de elite, de acordo com indicadores e } \\
\text { variáveis situacionais relacionadas ao espaço e } \\
\text { às tarefas. }\end{array}$ & $\begin{array}{c}\text { As tendências identificadas permitem aos } \\
\text { treinadores melhorar os planos estratégicos que } \\
\text { envolvem a seleção das abordagens ofensivas e } \\
\text { defensivas mais apropriadas para a realização de } \\
\text { posse de bola no futsal. }\end{array}$ \\
\hline 18 & $\begin{array}{l}\text { Sarmento et } \\
\text { al. (2015) }\end{array}$ & $\begin{array}{l}\text { Quantificar o tipo de sequencias ofensivas que } \\
\text { resultaram em gols no futsal de elite. }\end{array}$ & $\begin{array}{l}\text { O número de "transições" de defesa para ofensiva } \\
(\mathrm{n}=45) \text { e o início de jogadas ofensivas devido às } \\
\text { regras do jogo }(\mathrm{n}=45) \text { foram os tipos mais comuns } \\
\text { de sequências que resultaram em metas em } \\
\text { comparação com outros padrões de jogo. As zonas } \\
\text { ofensivas centrais foram as mais comuns para } \\
\text { chutes a gol, com } 73 \% \text { de todos os gols marcados } \\
\text { nessas zonas do campo em comparação com as } \\
\text { zonas defensivas e amplas. }\end{array}$ \\
\hline 19 & $\begin{array}{l}\text { Voser, Silva e } \\
\text { Voser (2016) }\end{array}$ & $\begin{array}{l}\text { Analisar a origem dos gols que ocorreram nos } \\
\text { jogos da Liga de Futsal de } 2014\end{array}$ & $\begin{array}{l}\text { Constatou-se que o contra-ataque obteve a maior } \\
\text { incidência na origem dos gols de toda a competição, } \\
\text { com } 25 \% \text {, totalizando } 104 \text { gols em } 58 \text { jogos, média } \\
\text { de } 1,79 \text { por do total dos jogos analisados }\end{array}$ \\
\hline 20 & $\begin{array}{l}\text { Travassos et } \\
\text { al. (2016) }\end{array}$ & $\begin{array}{l}\text { Este estudo avaliou as tendências de } \\
\text { flexibilidade/estabilidade dos comportamentos } \\
\text { coordenados em equipes internacionais de } \\
\text { futsal, considerados como sistemas coletivos } \\
\text { complexos, de acordo com as mudanças nas } \\
\text { formações defensivas de oposição. }\end{array}$ & $\begin{array}{l}\text { Os resultados revelaram propriedades semelhantes } \\
\text { de rede entre equipes quando competiam contra } \\
\text { formações defensivas mais arriscadas, enquanto } \\
\text { diferenças notáveis foram observadas contra } \\
\text { defesas conservadoras }\end{array}$ \\
\hline 21 & $\begin{array}{l}\text { Mocelin } \\
(2016)\end{array}$ & Avaliar a incidência de gols sofridos & $\begin{array}{l}\text { Os gols sofridos pela equipe na defesa em } \\
\text { inferioridade numérica, se deu pela diferença das } \\
\text { características da defesa, que é proposta pela } \\
\text { equipe, que usa marcação pressão, quando está em } \\
\text { igualdade numérica, e precisa marcar em zona } \\
\text { durante a defesa do goleiro linha. }\end{array}$ \\
\hline 22 & $\begin{array}{l}\text { Vicente- } \\
\text { Vila1e Lago- }\end{array}$ & $\begin{array}{l}\text { Identificar quais variáveis foram os melhores } \\
\text { preditores de sucesso na posse de bola de futsal }\end{array}$ & $\begin{array}{l}\text { Em geral, a maior eficácia de posse de bola foi } \\
\text { alcançada quando o goleiro participou como } \\
\text { jogador de campo regular }(p<0,01) \text {, a duração da }\end{array}$ \\
\hline
\end{tabular}




\begin{tabular}{|c|c|c|c|}
\hline & Peñas (2016) & com a participação do goleiro $4 \times 4$ e $5 \times 4$ & $\begin{array}{c}\text { posse de bola foi inferior a } 10 \mathrm{~s}(\mathrm{p}<0,01) \text {, a posse de } \\
\text { bola terminou na área de penalidade }(\mathrm{p}<0,01) \text { e a } \\
\text { pressão defensiva foi baixa }(\mathrm{p}<0,01) \text {. }\end{array}$ \\
\hline 23 & $\begin{array}{l}\text { Raiola e Tore } \\
\text { (2016) }\end{array}$ & $\begin{array}{l}\text { Verificar se os membros de uma amostra são } \\
\text { melhores em aprender habilidades específicas, } \\
\text { em comparação com um grupo de controle }\end{array}$ & $\begin{array}{c}\text { Estes resultados positivos sugerem o uso da análise } \\
\text { de vídeo como uma ferramenta no treinamento de } \\
\text { futsal, tanto para fins educacionais quanto de } \\
\text { desempenho. }\end{array}$ \\
\hline 24 & $\begin{array}{l}\text { Voser et al. } \\
\text { (2017) }\end{array}$ & $\begin{array}{l}\text { O objetivo desta investigação foi descrever a } \\
\text { relação entre a média de chutes em direção ao } \\
\text { gol e o resultado final dos jogos de futsal da } \\
\text { copa do mundo da Tailândia de } 2012\end{array}$ & $\begin{array}{c}\text { Conclui-se que as equipes que chutam mais em } \\
\text { direção ao gol apresentam uma probabilidade maior } \\
\text { de serem as vencedoras } \\
\text { nos jogos de Futsal profissional }\end{array}$ \\
\hline 25 & $\begin{array}{l}\text { Durães et al. } \\
\qquad(2017)\end{array}$ & $\begin{array}{l}\text { Verificar os níveis de ansiedade pré-competitiva } \\
\text { das atletas que disputam os Jogos de Minas } \\
\text { Gerais - 2015 - e a correlação deles com a } \\
\text { eficiência técnica e tática das mesmas }\end{array}$ & $\begin{array}{c}\text { Portanto, pode-se inferir que, apesar de alguns erros } \\
\text { técnicos } \\
\text { das jogadoras, os mesmos não podem ser } \\
\text { influenciados pela ansiedade, não havendo uma } \\
\text { correlação entre a ansiedade e as ações técnicas }\end{array}$ \\
\hline 26 & Leite (2017) & $\begin{array}{l}\text { Analisar o efeito de jogar em casa no futsal } \\
\text { profissional, fazendo uma análise e comparação } \\
\text { entre as } 10 \text { principais ligas nacionais do mundo. }\end{array}$ & $\begin{array}{l}\text { Somente na liga de futsal italiana não apresentou } \\
\text { resultado positivo, porcentagem de pontos ganhos } \\
\text { acima de } 50 \% \text { em favor das equipes que jogam em } \\
\text { casa. A porcentagem média encontrada neste estudo } \\
\text { para vantagem em casa foi de } 56,15 \pm 6,15 \% \text { do } \\
\text { total de pontos acumulados. }\end{array}$ \\
\hline 27 & $\begin{array}{l}\text { Giani Soares e } \\
\text { Silva (2018) }\end{array}$ & $\begin{array}{l}\text { Analisar os gols da Liga Espanhola de Futsal da } \\
\text { temporada 2015/2016. }\end{array}$ & $\begin{array}{l}\text { Verificou-se que o ataque posicional foi a ação } \\
\text { técnico-tática mais recorrente nos gols do } \\
\text { campeonato, com } 34 \% \text { dos gols, seguido do contra- } \\
\text { ataque com } 26 \% \text { e bola parada com } 22 \% \text {. O uso do } \\
\text { ataque de goleiro linha mostrou-se eficiente, uma } \\
\text { vez que } 8 \% \text { dos gols marcados na competição foi } \\
\text { com a utilização do ataque de goleiro linha, } \\
\text { enquanto } 6 \% \text { com a marcação de goleiro linha. }\end{array}$ \\
\hline 28 & $\begin{array}{c}\text { Angulo e } \\
\text { Angulo (2018) }\end{array}$ & $\begin{array}{c}\text { Analisar as características das diferentes } \\
\text { cobranças de escanteios realizadas na UEFA } \\
\text { Euro Futsal } 2016 .\end{array}$ & $\begin{array}{l}\text { Mais da metade dos chutes de escanteio }(55,55 \%) \\
\text { são marcados nos últimos minutos do primeiro } \\
\text { tempo; a maioria dos chutes de escanteio são } \\
\text { defendidos na defesa zonal; e os chutes de } \\
\text { escanteio, em termos de gols marcados, não são } \\
\text { determinantes para um desempenho esportivo } \\
\text { superior. }\end{array}$ \\
\hline 29 & $\begin{array}{l}\text { Souza et al. } \\
\quad(2018)\end{array}$ & $\begin{array}{c}\text { Analisar a utilização do goleiro-linha e linha- } \\
\text { goleiro no futsal, diferenciando essas duas } \\
\text { abordagens da utilização do goleiro, e } \\
\text { verificando a eficácia dessas ações tático } \\
\text { estratégicas }\end{array}$ & $\begin{array}{c}\text { Os resultados apontaram que o goleiro-linha é } \\
\text { utilizado nas jogadas de lateral e nas pressões } \\
\text { adversárias, havendo certo equilíbrio entre as etapas } \\
\text { do jogo, independe do placar e que os locais } \\
\text { padrões de recepção são dentro e a frente da área de } \\
\text { meta }\end{array}$ \\
\hline 30 & $\begin{array}{l}\text { Silva et al. } \\
\quad(2018)\end{array}$ & $\begin{array}{l}\text { Objetivo comparar os indicadores técnicos das } \\
\text { equipes vencedoras e perdedoras de cada } \\
\text { partida da fase eliminatória da Liga dos } \\
\text { Campeões, temporada 2014/2015. }\end{array}$ & $\begin{array}{l}\text { Conclui-se que as equipes vencedoras apresentam } \\
\text { diferenças significantes nos indicadores } \\
\text { técnicos demonstrando melhores resultados que as } \\
\text { equipes perdedoras. No entanto, as variáveis } \\
\text { técnicas de passes errados e desarmes não } \\
\text { demonstraram diferenças entre as equipes } \\
\text { vencedoras e perdedoras. }\end{array}$ \\
\hline 31 & $\begin{array}{l}\text { Voser et al. } \\
\quad(2018)\end{array}$ & $\begin{array}{c}\text { Verificar o período de maior incidência dos gols } \\
\text { na Taça Escolar de Futsal na categoria juvenil } \\
\text { no ano de } 2015\end{array}$ & $\begin{array}{l}\text { Este estudo concluiu que são nos últimos } 10 \\
\text { minutos de jogo que há maior incidência de gols }\end{array}$ \\
\hline 32 & $\begin{array}{c}\text { Da Silva et la. } \\
\text { (2019) }\end{array}$ & $\begin{array}{c}\text { Analisar e quantificar as ações das goleiras } \\
\text { durante uma competição estadual de futsal } \\
\text { feminino }\end{array}$ & $\begin{array}{l}\text { Os dados obtidos apresentaram que } 66.48 \% \text { foram } \\
\text { realizadas com as mãos, } 10.74 \% \text { defesas com os pés } \\
\text { e } 22.78 \% \text { defesas nas saídas do gol }\end{array}$ \\
\hline 33 & $\begin{array}{l}\text { Caldas et al. } \\
\qquad(2019)\end{array}$ & Quantificar as ações defensivas & $\begin{array}{l}\text { Observou-se que } 41,2 \% \text { das ações foram de } \\
\text { desarmes, seguidos por antecipação } 35,5 \% \text { e } \\
\text { bloqueio } 23,4 \% \text {. }\end{array}$ \\
\hline 34 & $\begin{array}{l}\text { Méndez et al. } \\
\text { (2019) }\end{array}$ & $\begin{array}{l}\text { Explorar o poder discriminatório das variáveis } \\
\text { relacionadas às tarefas e o contexto para } \\
\text { estabelecer diferenças nas ligas de elite de futsal }\end{array}$ & $\begin{array}{l}\text { Os resultados permitiram entender que as equipes } \\
\text { de Portugal e da Rússia utilizaram mais o ataque } \\
\text { posicional e menos o contra-ataque e do que os }\end{array}$ \\
\hline
\end{tabular}




\begin{tabular}{|c|c|c|c|}
\hline & & de Portugal, Espanha e Rússia & $\begin{array}{l}\text { espanhóis, que apresentam um perfil mais } \\
\text { equilibrado }\end{array}$ \\
\hline 35 & $\begin{array}{l}\text { Santos et al. } \\
\text { (2019) }\end{array}$ & $\begin{array}{c}\text { Identificar os indicadores de desempenho que } \\
\text { discriminam os jogadores all-stars dos não all- } \\
\text { stars e diferenciar as equipes perdedoras das } \\
\text { vencedoras. }\end{array}$ & $\begin{array}{l}\text { Indicadores que discriminaram jogadores all-stars } \\
\text { dos não all-stars (Minutos jogados, gols, } \\
\text { assistência, recuperação de bola, chute no gol, } \\
\text { passe-chave). Em relação a análise do time os } \\
\text { indicadores que discriminaram da equipe vencedora } \\
\text { da equipe perdedora (gols, assistências, contra- } \\
\text { ataque, bolas paradas). Entretanto apenas os gols e } \\
\text { bolas paradas previram o resultado da partida. }\end{array}$ \\
\hline 36 & $\begin{array}{l}\text { Amani- } \\
\text { Shalamzari et } \\
\text { al. (2019) }\end{array}$ & $\begin{array}{l}\text { Comparar um programa de treinamento de } 6 \\
\text { semanas de condicionamento baseado no Small } \\
\text { Sided and conditioning game (SSG) e baseado } \\
\text { na aptidão física tradicional e genérica a } \\
\text { capacidade aeróbica, potência anaeróbica e } \\
\text { agilidade dos jovens jogadores de futsal. }\end{array}$ & $\begin{array}{l}\text { Os resultados indicam o treinamento periodizado do } \\
\text { SSG modificando a dimensão da quadra e o número } \\
\text { de jogadores teve efeitos mais positivos sobre os } \\
\text { componentes tático-técnicos do que a GFT. } \\
\text { Os programas de treinamento dos SSGs podem } \\
\text { contribuir para otimizar o tempo de treinamento } \\
\text { melhorando tanto o desempenho físico quanto } \\
\text { técnico/tático. }\end{array}$ \\
\hline 37 & $\begin{array}{l}\text { Gómez et al. } \\
\text { (2019) }\end{array}$ & $\begin{array}{l}\text { Analisar o efeito das demissões dos jogadores } \\
\text { no resultado dos ataques em partidas de elite de } \\
\text { futsal e estabelecer o perfil de desempenho dos } \\
\text { ataques feitos em superioridade numérica pelas } \\
\text { equipes de elite de futsal }\end{array}$ & $\begin{array}{l}\text { Os resultados da regressão logística binária (gol ou } \\
\text { não gol) mostraram que a maior eficácia de ataque } \\
\text { foi alcançada quando as equipes jogam em casa, } \\
\text { realizam o ataque durante os minutos 33-36 e a } \\
\text { equipe adversária tem } 3 \text { faltas. }\end{array}$ \\
\hline 38 & $\begin{array}{l}\text { Méndez et al. } \\
\qquad(2019)\end{array}$ & $\begin{array}{l}\text { Identificar a importância da chance do goleiro } \\
\text { de chutar a gol como um jogador de linha elite, } \\
\text { de acordo com variáveis críticas e situacionais }\end{array}$ & $\begin{array}{l}\text { Quando as equipes estavam empatando ou } \\
\text { perdendo, as ações do goleiro como jogador de fora } \\
\text { de campo foram malsucedidas }\end{array}$ \\
\hline 39 & $\begin{array}{l}\text { Méndez- } \\
\text { Domínguez et } \\
\text { al. (2019) }\end{array}$ & $\begin{array}{l}\text { O objetivo deste estudo foi identificar a } \\
\text { importância e o significado das metas usando o } \\
\text { goleiro como um jogador de fora de campo no } \\
\text { futsal de elite, de acordo com variáveis críticas } \\
\text { e situacionais }\end{array}$ & $\begin{array}{c}\text { As tendências identificadas permitirão aos } \\
\text { treinadores de futsal reconhecer as situações mais } \\
\text { adequadas para alcançar a eficácia ao utilizar o } \\
\text { goleiro como uma estratégia de jogador de fora de } \\
\text { campo }\end{array}$ \\
\hline 40 & $\begin{array}{l}\text { Pizarro et al. } \\
\text { (2019) }\end{array}$ & $\begin{array}{c}\text { Analisar o efeito de um programa de } \\
\text { intervenção, com base na pedagogia não linear, } \\
\text { na tomada de decisão e execução de diferentes } \\
\text { ações no futsal. }\end{array}$ & $\begin{array}{l}\text { Valores significativamente mais altos na tomada de } \\
\text { decisões e execução no primeiro e segundo } \\
\text { princípios, mas não no terceiro. Na ação de drible, } \\
\text { os resultados mostraram valores significativamente } \\
\text { mais altos na tomada de decisão no segundo e } \\
\text { terceiro princípios, mas não no primeiro. No } \\
\text { entanto, não foram encontradas diferenças } \\
\text { significativas nas ações dos chutes. }\end{array}$ \\
\hline 41 & $\begin{array}{l}\text { Corrêa et al. } \\
\text { (2019) }\end{array}$ & $\begin{array}{l}\text { Este estudo investigou como jogadores de futsal } \\
\text { lidam visualmente com informações em } \\
\text { cenários de coordenação interpessoal ao tomar } \\
\text { decisões sobre tiroteios. }\end{array}$ & $\begin{array}{c}\text { Quanto maior o tempo de posse de bola, maior a } \\
\text { variabilidade na busca visual. Parece que, através } \\
\text { da busca visual, os jogadores buscam a mesma - } \\
\text { ótima - relação interpessoal angular. }\end{array}$ \\
\hline 42 & $\begin{array}{l}\text { Ismail e } \\
\text { Nunome } \\
(2019)\end{array}$ & $\begin{array}{l}\text { Investigar a eficácia da posse da bola no futsal } \\
\text { com outros indicadores chaves de desempenho } \\
\text { na Copa do Mundo de Futsal de } 2016 \text {. }\end{array}$ & $\begin{array}{l}\text { As equipes que venceram partidas e as melhores } \\
\text { equipes classificadas obtiveram um número total } \\
\text { significativamente maior de tentativas de chutes } \\
(\mathrm{p}<0,01) \text { e índice total de posse de bola }(\mathrm{p}<0,01) \text { do } \\
\text { que seus adversários. }\end{array}$ \\
\hline 43 & $\begin{array}{l}\text { Szwarc e } \\
\text { Oszmaniec } \\
\quad(2020)\end{array}$ & $\begin{array}{l}\text { Desenvolver um modelo de eficiência das ações } \\
\text { dos goleiros das equipes de futsal de alto nível }\end{array}$ & $\begin{array}{l}\text { No ataque, eles aplicam ações estritamente } \\
\text { dependentes dos parceiros (cooperação) com mais } \\
\text { frequência, enquanto na defesa, as ações são } \\
\text { relativamente dependentes dos parceiros (ações } \\
\text { individuais) }\end{array}$ \\
\hline 44 & $\begin{array}{l}\text { Ueda et al. } \\
\text { (2020) }\end{array}$ & $\begin{array}{c}\text { Analisar os princípios táticos ofensivos centrais } \\
\text { e a eficiência técnica dos jogadores de futsal do } \\
\text { ensino fundamental. }\end{array}$ & $\begin{array}{c}\text { Verificou-se que o princípio tático "cobertura } \\
\text { ofensiva" foi mais frequentemente executado pelos } \\
\text { jogadores de futsal da escola primária }(\mathrm{p}=0,01) \text {, } \\
\text { seguido por "largura e comprimento" sem bola }(\mathrm{p}< \\
0,01) \text {. }\end{array}$ \\
\hline 45 & $\begin{array}{l}\text { Yiannaki et al. } \\
\qquad(2020)\end{array}$ & $\begin{array}{l}\text { Examinar características selecionadas de } \\
\text { desempenho físico (cargas internas e externas) e } \\
\text { técnico em partidas internacionais de futsal, a } \\
\text { fim de estudar o potencial destas para a }\end{array}$ & $\begin{array}{l}\text { As estatísticas da equipe incluíam } 647 \text { passes, } ~ 51 \\
\text { dribles e } 78 \text { eventos de jogo definidos por equipe } \\
\text { por jogo. Análises de jogo mostraram que } 77,3 \% \\
\text { das recepções de bola foram completadas com a }\end{array}$ \\
\hline
\end{tabular}




\begin{tabular}{|c|c|c|c|}
\hline & & $\begin{array}{l}\text { transferência de habilidades e auxílio ao } \\
\text { desenvolvimento do jogador de futebol. }\end{array}$ & $\begin{array}{l}\text { sola do pé. A avaliação de dois pés mostrou } \\
80,1 \pm 16,7 \% \text { das posses individuais utilizaram o pé } \\
\text { dominante para receber e } 84,1 \pm 10,7 \% \text { para passar a } \\
\text { bola, mostrando assim um forte domínio do pé. }\end{array}$ \\
\hline 46 & $\begin{array}{l}\text { Milanez et al. } \\
\qquad(2020)\end{array}$ & $\begin{array}{c}\text { Analisar a relação entre desempenho da corrida } \\
\text { e passes, bem como o efeito de substituições e o } \\
\text { nível competitivo nessas variáveis, durante } \\
\text { jogos oficiais de futsal. }\end{array}$ & $\begin{array}{l}\text { Os jogadores adultos demonstraram que a queda de } \\
\text { desempenho na corrida e passes bem-sucedidos em } \\
\text { um jogo de futsal pode ser observada a partir do } \\
\text { segundo trimestre, e não apenas no segundo tempo, } \\
\text { como mostrado em estudos anteriores no futsal. A } \\
\text { substituição de jogadores é uma estratégia } \\
\text { importante a ser utilizada pelos treinadores para } \\
\text { melhorar o desempenho na corrida e nos passes em } \\
\text { jogos de futsal. }\end{array}$ \\
\hline 47 & $\begin{array}{l}\text { De Moraes et } \\
\text { al. }(2020)\end{array}$ & $\begin{array}{l}\text { Analisar a frequência de gols das partidas de } \\
\text { Futsal da Liga Nacional de Futsal de } 2018\end{array}$ & $\begin{array}{l}\text { A média de gols foi superior nos últimos cinco } \\
\text { minutos finais dos jogos em relação aos demais } \\
\text { períodos e equipes mandantes do jogo marcam mais } \\
\text { gols que as equipes visitantes. }\end{array}$ \\
\hline 48 & Kurogi (2020) & $\begin{array}{l}\text { Descrever os fundamentos técnico-tácticos } \\
\text { ofensivos mais utilizados pela seleção } \\
\text { espanhola de futsal, bem como as zonas de } \\
\text { contato onde cada um desses fundamentos é } \\
\text { mais frequentemente iniciado. }\end{array}$ & $\begin{array}{l}\text { Maior realização do controle da bola com a sola do } \\
\text { pé, passe com o interior do pé, condução com o } \\
\text { peito do pé, drible diversas superfícies do pé e o } \\
\text { chute com o peito do pé. }\end{array}$ \\
\hline 49 & $\begin{array}{l}\text { Pizarro et al. } \\
\qquad(2020)\end{array}$ & $\begin{array}{c}\text { Analisar os efeitos indiretos de um programa de } \\
\text { intervenção, baseado em PNL (desenho de } \\
\text { tarefas baseado em princípios táticos de ataque } \\
\text { e vantagem numérica da equipe atacante), na } \\
\text { tomada de decisões (DM) e execução (Ex) em } \\
\text { ações técnico-táticas defensivas no futsal sub- } \\
16 .\end{array}$ & $\begin{array}{l}\text { A abordagem de PNL é uma estrutura teórica } \\
\text { apropriada para melhorar a aquisição de } \\
\text { comportamento tático defensivo no futsal }\end{array}$ \\
\hline 50 & $\begin{array}{c}\text { Rother e } \\
\text { Scalco }(2020)\end{array}$ & $\begin{array}{l}\text { Comparar a origem de gols marcados como } \\
\text { mandante e visitante de uma equipe de futsal }\end{array}$ & $\begin{array}{l}\text { Há um equilíbrio entre a forma de realização dos } \\
\text { gols, embora ocorram mais quando a equipe é } \\
\text { mandante sobre quando é visitante }\end{array}$ \\
\hline
\end{tabular}

Fonte: Autores (2021).

A Tabela 1 apresenta os 50 artigos contemplados na presente revisão integrativa, bem como as informações mais relevantes acerca dos estudos analisados, como o sexo, amostra analisada, nível da competição e fator analisado, na Tabela 2 apresenta as revistas científicas que mais publicaram sobre a temática. 
Tabela 1. Frequência de artigos científicos retornados.

\begin{tabular}{|c|c|c|}
\hline & Número de referência & $\begin{array}{l}\text { Frequên } \\
\text { cia }(\%)\end{array}$ \\
\hline \multicolumn{3}{|l|}{ Sexo } \\
\hline Feminino & $4,25,32,33$ & $4(8)$ \\
\hline Masculino & $\begin{array}{l}1,2,3,6,7,8,10,13,14,15,16,17,19,20,21,22,24,26,28,31,34,36,38,39,40, \\
41,42,43,46,47,48,49,50\end{array}$ & $33(66)$ \\
\hline Não identificado & $5,9,11,12,18,23,27,29,30,35,37,44,45$ & $13(26)$ \\
\hline \multicolumn{3}{|c|}{ Participantes analisados } \\
\hline Goleiro & $22,29,32,38,43$ & $5(10)$ \\
\hline Jogador de linha & $\begin{array}{l}1,3,4,6,8,9,10,11,13,14,15,16,17,20,23,24,28,30,31,33,35,36,37,39,40, \\
45,46,47,48,49,50\end{array}$ & $31(62)$ \\
\hline Ambos & $2,5,7,12,18,19,21,25,26,27,34,41,42,44$ & $14(28)$ \\
\hline \multicolumn{3}{|c|}{ Nível das equipes analisadas } \\
\hline Escolar & 23,40 & $2(4)$ \\
\hline Regional & $2,25,31,44,49$ & $5(10)$ \\
\hline Estadual & $5,12,15,32,33,46^{*}, 50$ & $7(14)$ \\
\hline Nacional & $\begin{array}{l}1,3,4,6,7,9,10,11,13,14,16,17,18,19,21,22,26,27,29,30,36,37,38,39,46 * \\
47\end{array}$ & $26(52)$ \\
\hline Internacional & $8,20,24,28,34,35,43,45,48,42$ & $10(20)$ \\
\hline Não identificado & 41 & $1(2)$ \\
\hline \multicolumn{3}{|l|}{ Fator analisado } \\
\hline Jogadores & $3,6,7,29,36,45$ & $6(12)$ \\
\hline Jogos & $\begin{array}{l}1,2,4,8,9,11,12,13,14,15,16,17,19,20,21,22,24,26,27,30,31,32,33,34,35 \\
, 37,38,39,42,43,46,47,48,50\end{array}$ & $34(68)$ \\
\hline Jogo e jogador & $5,18,25,41$ & $4(8)$ \\
\hline Treino & $23,40,49$ & $3(6)$ \\
\hline Não identificado & $10,28,44$ & $3(6)$ \\
\hline
\end{tabular}

*: o mesmo artigo com duas características. Fonte: Autores (2021).

Tabela 2. Os periódicos científicos que mais publicaram sobre a temática.

\begin{tabular}{lcc}
\hline Título da revista & JCR & Frequência (\%) \\
\hline Revista Brasileira de Futsal e Futebol & $\mathbf{( 2 0 2 1 )}$ & $14(28)$ \\
International Journal of Performance Analysis in Sport & - & $6(12)$ \\
Journal of Sports Sciences & 3,95 & $6(12)$ \\
Human Movement Science & 2,161 & $2(4)$ \\
Revista Brasileira da Cineantropometria e do Desempenho & - & $2(4)$ \\
Humano & - & $2(4)$ \\
Revista Portuguesa de Ciências do Desporto & 2,815 & $2(4)$ \\
Science and Medicine in Football & \\
\hline
\end{tabular}

JCR: Journal Citation Reports. Fonte: Autores (2021). 
Dos 50 artigos selecionados 66\% são estudos com jogadores masculinos, $8 \%$ são estudos com jogadoras femininas e $26 \%$ foram estudos que não mencionaram o sexo da amostra. Nota-se que a quantidade de artigos que não identificaram o sexo da amostra analisada foi alta, isso serve de alerta para os autores, pois a descrição da amostra, incluindo o sexo, é de extrema importância para o entendimento da pesquisa por outros pesquisadores, a fim de compará-lo ou replicá-lo em futuras pesquisas.

Em um panorama geral, os jogadores de linha foram os mais investigados (62\%) em relação aos goleiros (10\%). Já o nível da competição mais analisada foi a nacional (52\%), achado este interessante, pois permite aos pesquisadores fazerem comparações com jogos e jogadores de outros países.

Analisar o contexto do jogo (68\%) foi o de maior interesse pelos pesquisadores da área em relação aos jogadores (12\%) e ao treino (6\%), fato compreensivo, pois possibilita aos pesquisadores abarcarem diversas ações defensivas e ofensivas, sendo elas técnicas e táticas ao mesmo tempo com o intuito de inserirem na rotina do treinamento. Já em relação ao periódico de maior quantidade de publicações sobre o tema foi a Revista Brasileira de Futsal e Futebol - RBFF (28\%), seguida pela International Journal of Performance Analysis in Sport (12\%) e Journal of Sports Sciences (12\%), sendo as duas últimas com valores de JCR de 1,95 e 3,337, respectivamente.

Quanto ao ano de publicação, o ano que mais publicou sobre a análise de desempenho técnico-tático no futsal foi o ano de 2019 (22\%), seguido pelo ano de 2020 (16\%), 2015 (10\%), 2016 (10\%) e 2018 (10\%). Nos últimos três anos representou $48 \%$ de toda publicação sobre a análise de desempenho técnico-tático no futsal, demonstrando ser uma área em exponencial, que recebe cada vez mais atenção e atuação na ciência e nas comissões técnicas.

Quanto às ações analisadas, foram investigadas um total de 238 ações, destas 30 (12,6\%) ações referentes ao passe, 29 $(12,18 \%)$ ações referentes ao chute e $21(8,8 \%)$ foram ações referentes ao gol. Além disso, as 238 ações foram representadas relativamente pelos seus atributos técnico $(65,97 \%)$, tático $(19,75 \%)$, do goleiro $(8,4 \%)$ e das bolas paradas $(5,88 \%)$.

Quanto aos autores que mais publicaram sobre a temática, a tabela a seguir apresentará o ranking dos 10 autores que mais contribuíram com publicações de estudos acadêmicos sobre a temática da análise de desempenho no futsal, a quantidade que cada um publicou sobre a temática, o link para acessar os seus respectivos ResearchGate e a Instituição vinculada atual.

Tabela 3. O ranking dos 10 autores que mais publicaram sobre a temática.

\begin{tabular}{|c|c|c|c|}
\hline $\begin{array}{l}\text { Nome do } \\
\text { autor }\end{array}$ & $\mathbf{Q P}$ & ResearchGate & Universidade - País \\
\hline $\begin{array}{l}\text { Travassos, } \\
\text { B }\end{array}$ & 10 & $\begin{array}{l}\text { https://www.researchgate.net/profile/Bruno_Travas } \\
\text { sos }\end{array}$ & $\begin{array}{c}\text { Universidade da Beira Interior - } \\
\text { PT }\end{array}$ \\
\hline $\begin{array}{l}\text { Gómez, } \\
\text { MA }\end{array}$ & 5 & $\begin{array}{l}\text { https://www.researchgate.net/profile/Miguel_Ruan } \\
\text { o }\end{array}$ & $\begin{array}{l}\text { Universidad Politécnica de } \\
\text { Madrid - ES }\end{array}$ \\
\hline $\begin{array}{l}\text { Méndez, } \\
\text { CD }\end{array}$ & 5 & $\begin{array}{l}\text { https://www.researchgate.net/profile/Cesar_Mende } \\
\text { z-Dominguez2 }\end{array}$ & $\begin{array}{l}\text { Universidad Politécnica de } \\
\text { Madrid - ES }\end{array}$ \\
\hline Voser, RC & 5 & $\begin{array}{l}\text { https://www.researchgate.net/profile/Rogerio_Vose } \\
\text { r }\end{array}$ & $\begin{array}{l}\text { Universidade Federal do Rio } \\
\text { Grande do Sul - BR }\end{array}$ \\
\hline Davids, K & 4 & 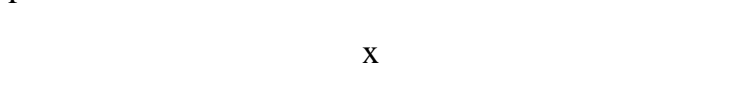 & $\begin{array}{l}\text { Queensland University of } \\
\text { Technology - AU }\end{array}$ \\
\hline Rúiz, LM & 4 & https://www.researchgate.net/profile/Luis_Ruiz17 & $\begin{array}{c}\text { Universidad Politécnica de } \\
\text { Madrid - ES }\end{array}$ \\
\hline $\begin{array}{l}\text { Cardoso, } \\
\text { MS }\end{array}$ & 3 & $\begin{array}{l}\text { https://www.researchgate.net/profile/Marcelo_Card } \\
\text { oso }\end{array}$ & $\begin{array}{l}\text { Universidade Federal do Rio } \\
\text { Grande do Sul - BR }\end{array}$ \\
\hline Moraes, JC & 3 & https://www.researchgate.net/profile/Jose_Moraes5 & $\begin{array}{c}\text { Universidade Federal do Rio } \\
\text { Grande do Sul - BR }\end{array}$ \\
\hline Vilar, L & 3 & https://www.researchgate.net/profile/Luis_Vilar & Universidade Europeia - PT \\
\hline Voser, PEG & 3 & $\mathrm{x}$ & $\mathrm{x}$ \\
\hline
\end{tabular}

QP: quantidade de publicação; PT: Portugal; BR: Brasil; ES: Espanha; AU: Austrália. Fonte: Autores (2021). 


\section{Discussão}

O objetivo da presente revisão integrativa foi compilar informações disponibilizadas na literatura quanto aos estudos sobre a análise de desempenho no futsal, bem como traçar a realidade que a produção científica se encontra sobre a temática.

Não diferente da modalidade do futebol, o futsal feminino foi menos estudado em relação ao masculino. Este cenário ainda é um alerta para que futuras pesquisas possam estar voltadas ao público feminino. Apesar de ser a mesma modalidade, o sexo interfere na construção dos períodos do treinamento, em que os treinadores necessitam de mais bases científicas para que possam embasar seus treinos em achados mais confiáveis, minimizando os achismos no esporte. Tais achados podem ser encontrados, também, na psicologia do esporte, em que construtos psicológicos são mais estudados em jogadores masculinos do que no feminino, deixando assim muitas lacunas sobre os aspectos físico, técnico, tático e psicológico no público feminino para serem investigados (Nascimento Junior et al., 2013; 2017; 2019; 2018 Bim et al., 2014).

Os goleiros são jogadores pouco estudados, mesmo sabendo da sua importância em quadra ainda são escassas pesquisas voltadas a este tipo de jogador no futsal e em outras modalidades, como é visto no futebol. O presente corroborou com outros estudos de revisão no futebol, onde os goleiros foram menos explorados em relação as outras funções dentro do campo (Sarmento et al., 2014; 2018). Tornando assim, uma área bem produtiva para outras pesquisas com estes jogadores.

Quanto ao ano de publicação, as publicações relacionadas a análise de desempenho no futsal por meio de observações obtiveram seus primeiros registros no ano de 2005 com o estudo de Amaral e Garganta11, em que objetivou analisar o drible e concluíram que o drible de progressão e o drible para remate são os tipos de 1x1 que mais provocam o desequilíbrio defensivo do adversário. Sabe-se que achados como este já vem mudando por meio de novos estudos, como por exemplo, o estudo de Santos et al. (2019), em que enfatiza o passe de ruptura sendo um bom indicador para vencer jogos e discriminar um excelente jogador dos demais.

O futsal está em constante evolução e devido a isso, há necessidade de que pesquisas sejam realizadas na modalidade a todo momento. É notório que o cenário vem mudando, pois, o interesse aumentou na comunidade científica sobre a temática nos últimos três anos e, com chances que nos anos seguintes superem. Mas, ainda há muito a ser estudado sobre a influência que as ações técnicas têm sobre o desempenho individual e coletivo em equipes de futsal.

No futsal, as ações mais analisadas foram o gol, chute e o passe. O interesse em estudar a origem dos gols vem tendo destaque no contexto acadêmico (Campos, 2014; Schneider et al., 2015; Mocelin, 2016), com implicações práticas pertinentes na rotina dos treinamentos, como por exemplo, treinar o contra-ataque é de extrema importância, pois Voser, Voser e Silva (2016) concluíram em suas pesquisas que o contra-ataque obteve a maior incidência na origem dos gols numa competição nacional, com 25\%, totalizando 104 gols em 58 jogos, média de 1,79 por jogo analisado. O atributo mais estudado foi o técnico e os atributos como o tático, ações do goleiro e as bolas paradas ainda é uma área que necessita de mais exploração, devido a sua importância dentro de uma partida de futsal e, principalmente registros no futsal para futuras comparações por outras pesquisas.

Os autores que mais publicaram sobre a temática, encontram-se descritos na tabela 3. Dando destaque ao pesquisador Bruno Travassos da Universidade da Beira Interior em Portugal e ao professor pesquisador Rogério Cunha Voser do Brasil, ambos pesquisadores obtêm uma expressiva contribuição para a modalidade em seus países e no mundo, com publicações contemplando aspectos físicos, técnicos, táticos e psicológicos em atletas de futsal. Vale salientar que os autores são oriundos das três melhores seleções classificadas mundialmente - Brasil, Espanha e Portugal, tais achados potencializam a importância que a ciência tem sobre o esporte, em específico ao futsal, obtendo uma associação positiva com a classificação mundial e a quantidade de publicações originadas do país. 


\section{Considerações Finais}

Conclui que o futsal masculino foi mais estudado que o feminino. As ações mais analisadas foram o gol, chute e o passe em jogadores de linha. Vale destacar três revistas científicas na presente revisão, a Revista Brasileira de Futsal e Futebol, International Journal of Performance Analysis in Sport e Journal of Sports Sciences, que somadas possuem mais da metade das publicações sobre a temática.

Em suma, os achados da presente revisão confirmam que há pouca exploração na análise que possam influenciar no desempenho de jogadores de futsal, ocasionando uma lacuna na literatura acadêmica, e um terreno fértil para os pesquisadores acadêmicos e profissionais da área para explorarem. Recomenda-se mais estudos direcionados ao futsal feminino, goleiros e em ações defensivas (desarmes, roubada de bola e interceptações).

Nota-se um maior interesse sobre a análise de desempenho no contexto do futsal, sabendo que esta contribui substancialmente por meios dos achados para a evolução técnica, tática, física e psicológica das equipes, os autores sugerem que as comissões técnicas se atentem mais para esta área, melhorando e qualificando as possibilidades de trabalho e a evolução de sua equipe. Por outro lado, cria-se uma lacuna de inserção de mais uma profissão dentro de uma comissão técnica, aumentando o leque de possibilidade de admissão no mercado de trabalho.

\section{Referências}

Álvarez-Kurogi, L. (2020). Technical-tactical offensive analysis with ball of the spanish team of futsal. Revista Internacional de Medicina y Ciencias de la Actividad Física y el Deporte, 20 (79), 453-470. http://doi.org/10.15366/rimcafd2020.79.005

Alvurdu, S. (2013). UEFA futsal euro 2012: technical and tactical analysis of turkish futsal national team. Pamukkale Journal of Sport Sciences. 4 (special issue), 104-110.

Amani-Shalamzari, S., Khoshghadam, E., Donyaei, A., Parnow, A., Bayati, M. \& Clemente, F. M. (2019). Generic vs. Small-sided game training in futsal: effects on aerobic capacity, anaerobic power and agility. Physiology \& Behavior. 204, 347-354. https://doi.org/10.1016/j.physbeh.2019.03.017

Amaral, R. \& Garganta J. (2005). A modelação do jogo em futsal: análise sequencial do 1x1 no processo ofensivo. Revista Portuguesa de Ciências do Desporto. 5 (3), 298-310.

Bacconi, A. \& Marella, M. (1995). Nuevo sistema di analisi dela partita in tempo reale. Cittá de Catelo. Nuova Prhomos.

Barreira, D. (2013). Tendências evolutivas da dinâmica tática em futebol de alto rendimento: estudo da fase ofensiva nos campeonatos da Europa e do mundo, entre 1982 e 2010. [Tese de doutorado]. Porto: Faculdade de Desporto da Universidade do Porto.

Bim, R. H., Nascimento Junior, J. R. A., Amorim, A. C., Vieira, J. L. L. \& Fiorese, L. (2014). Estratégias de coping e sintomas de burnout em atletas de futsal de alto rendimento. Revista Brasileira Ciência do Movimento. 22 (3), 69-75. http://dx.doi.org/10.18511/rbcm.v22i3.4351

Burachid, L. M. C., Silva, S. R., Soares, V. O. V., Santos, H. F. S. \& Greco, P. J. (2010). O comportamento tático em diferentes categorias na execução do contra-ataque no futsal. Revista Arquivos de Ciências da Saúde. 14 (2), 133-137.

Caldas, E. S., Silva, D. M. B., Miranda, B. L. G., Silva, E. A. V., Marques, R. F. \& Araújo, M. L. (2019). Análise dos fundamentos técnicos defensivos durante competições de Futsal Feminino. Revista Brasileira de Futsal e Futebol. 11 (44), 324-327.

Campos, J. M. (2014). Análise dos gols em jogos de futsal sub-17 no Campeonato Estadual de São Paulo 2012. Revista Brasileira de Futsal e Futebol. 6 (19), 27-31.

Carling, C., Reilly, T. \& Williams, A. M. (2008). Performance assessment for field sports. London. Routledge.

Contreras, M. \& Pino, J. (2000). La observación em los deportes de equipo. EFDeportes. 18 (5), 1.

Godik, M. \& Popov, A. (1993). La preparación física del fútbolista. Barcelona. Paidotribo.

Corrêa, U.C., Oliveira, T. A. C. D., Clavijo, F. A. R., Silva, L. S. \& Zalla, S. (2020). Time of ball possession and visual search in the decision-making on shooting in the sport of futsal. International Journal of Performance Analysis in Sport. 20 (2), 254-263. https://doi.org/10.1080/24748668.2020.1741916

Doğramac, S. N., Watsford, M. L. \& Murphy, A. J. (2015). Activity Profile Differences Between Sub-elite Futsal Teams. International Journal of Exercise Science. 8 (2), 112-123. https://digitalcommons.wku.edu/ijes/vol8/iss2/2

Doğramac, S. N., Watsford, M. L. \& Murphy, A. J. (2015). Changes in futsal activity profiles in a multiday tournament. Journal of Sports Medicine and Physical Fitness. 55 (7-8), 722-779.

Duraes, G. M. et al. (2017). Níveis de ansiedade pré-competitiva e eficiência técnica e tática de uma equipe adulta de futsal feminino participante dos jogos de minas gerais - 2015. Revista Portuguesa de Ciências do Desporto. 17 (s2.a), 127-140. 
García-Ângulo, A. \& García-Ângulo, F. J. (2018). Análisis de los saques de esquina en relación con el rendimiento en la UEFA Euro Futsal 2016. Journal of Sport and Health Research. 10 (3), 403-414.

Giani, G., Soares; G. F. \& Silva, S. A. (2018). Análise dos parâmetros técnico-tático dos gols da Liga Espanhola de Futsal 2015/2016. Revista Brasileira de Futsal e Futebol. 10 (36), 69-76.

Gómez, M. Á., Moral, J. \& Lago-Peñas C. (2015). Multivariate analysis of ball possessions effectiveness in elite futsal. Journal of Sports Sciences. 33 (20), 2173-2181.

Gómez, M. A., Méndez, C., Indaburu, A. \& Travassos, B. (2018). Goal effectiveness after players' dismissals in professional futsal teams. Journal of Sports Sciences. https://doi.org/10.1080/02640414.2018.1531498

Heyvaert, M. \& Onghena, P. (2013). Mixed methods research synthesis: definition, framework and potential. Quality \& Quantity. 47, 659-676. https://doi.org/10.1007/s11135-011-9538-6

Hughes, M. \& Bartlett, R. (2008). What is performance analysis? In: M, Hughes. I, Franks. The essentials of performance analysis: na introduction. London. Routledge. p. 118-140.

Ismail, S. I., Nunome, H. (2019). The key performance indicators that discriminate winning and losing, and successful and unsuccessful teams during 2016 FIFA Futsal World Cup. Science \& Medicine in Football. https://doi.org/10.1080/24733938.2019.1662937

Jovanovic, M., Sporis, G. \& Milanovic, Z. (2011). Differences in situational and morphological parameters between male soccer and futsal: a comparative study. International Journal of Performance Analysis in Sport. 11 (2), 227-238. https://doi.org/10.1080/24748668.2011.11868544

Junior, D. R. (2002). A competição como fonte de estresse no esporte. Revista Brasileira de Ciência e Movimento. 10 (4), 19-26.

Lapresa, D., Alvarez, L., Arana, J., Garzón, B. \& Caballero, V. (2013). Observational analysis of the offensive sequences that ended in a shot by the winning team of the 2010 UEFA Futsal Championship. Journal of Sports Sciences. 31 (15), 1731-9. https://doi.org/10.1080/02640414.2013.803584

Leite, W. S. S. (2017). The effect of home advantage in professional futsal. Trends in Sport Science. 2 (24), 81-85.

Méndez, C., Gómez, M. A., Rúiz, L. M. \& Travassos, B. (2019). Goalkeeper as an outfield player: shooting chances at critical moments in elite futsal. International Journal of Performance Analysis in Sport. https://doi.org/10.1080/24748668.2019.1581967

Méndez, C., Gómez, M. A., Rúiz, L. M. \& Travassos, B. (2019). Goals scored and received in 5vs4 gk game strategy are constrained by critical moment and situational variables in elite futsal. Journal of Sports Sciences. 37 (21), 2443-2451. http://dx.doi.org/10.1080/02640414.2019.1640567

Méndez, C., Gonçalves, B., Santos, J., Ribeiro, J. N. \& Travassos, B. (2019). Attacking profiles of the best ranked teams from elite futsal leagues. Frontiers Psychology. 10, 1370. https://doi.org/10.3389/fpsyg.2019.01370

Mocelin, R. (2016). Análise dos gols sofridos pela equipe da Associação Carlos Barbosa de Futsal-RS, e a incidência de gols sofridos na defesa do goleiro linha, durante a Liga Nacional de Futsal 2015. Revista Brasileira de Futsal e Futebol. 8 (30), 294-298.

Moraes, G. A., Crippa, J. D., Leme, A. F. \& Chiminazzo, J. G. C. (2020). Liga nacional de futsal 2018: análise da incidência de gols. Revista Brasileira de Futsal e Futebol, 12 (48), 202-208.

Milanez, V. F., Bueno, M. J., Caetano, F. G., Chierotti, P., Moraes, S. M. \& Moura, F. (2020). Relationship between number of substitutions, running performance and passing during under-17 and adult official futsal matches. International Journal of Performance Analysis in Sport. 20, 470-482. https://doi.org/10.1080/24748668.2020.1761673

Miloski, B., Pinho, J. P., Freitas, C. G., Marcelino, P. R. \& Arruda, A. F. S. (2014). Quais ações técnico-táticas realizadas durante as partidas de futsal podem discriminar o resultado de vitória ou derrota? Revista Brasileira de Educação Física e Esporte. 28 (2), 203-209. http://dx.doi.org/10.1590/180755092014000200203

Muller, E. S., Teoldo, I. \& Garganta, J. (2018). Tactical analysis in futsal: comparative study of performance by players from four age levels. Revista Brasileira de Ciências do Esporte. 40 (3), 248-256. https://doi.org/10.1016/j.rbce.2016.01.015

Nascimento Júnior, J. R. A., Vissoci, J. R. N., Lavallee, D., Codonhato, R., Do Nascimento, J. V. \& Fiorese, L. (2017). The mediating role of basic needs satisfaction on the relationship of perfectionism traits and team cohesion among elite futsal athletes. International Journal of Sport Psychology. 48, 591-609. http://dx.doi.org/10.7352/IJSP2017.48.591

Nascimento Júnior, J. R. A. \& Vieira, L. F. (2013). Group cohesion and coach leadership based on the competitive level of teams in the context of Paraná indoor soccer. Revista Brasileira de Cineantropometria \& Desempenho Humano. 15 (1), 89-102.

Nascimento Júnior, J. R. A., Granja, C. T. L., Silva, A. A., Fortes, L. S., Gonçalbes, M. P., Oliveira, D. V. \& Fiorese, L. (2019). Association between basic psychological needs of the self-determination theory and perception of group cohesion among high-performance futsal athletes. Revista Brasileira de Cineantropometria \& Desempenho Humano, 21, e57369. https://doi.org/10.5007/1980-0037.2019v21e57369

Nascimento Júnior, J. R. A., Granja, C. T. L., Da Silva, E. C., Amorim, D. R., Oliveira, D. V. \& Fiorese, L. (2018). Frequency of matches as starter and team time are intervening factors on group cohesion perception in the high performance futsal context? Revista Inspirar: Movimento \& Saúde. 16 (2), $26-31$.

Pizarro, D., Práxedes, A., Travassos, B. \& Moreno, A. (2020). Development of defensive actions in small-sided and conditioned games with offensive purposes in futsal. Frontiers Psychology, 11, 591-572. http://doi.org/10.3389/fpsyg.2020.591572 
Pizarro, D., Práxedes, A., Travassos, B., Villar, F. \& Moreno, A. (2019). The effects of a nonlinear pedagogy training program in the technical-tactical behaviour of youth futsal players. International Journal of Sports Science \& Coaching. 14 (1), 15-23. https://doi.org/10.1177\%2F1747954118812072

Raiola, G. \& Tore, P. A. (2016). The use of video analysis in futsal as a tool in physical education and sport teaching method. Acta Kinesiologica. 10 (2), 41 45 .

Rother, R., Scalco, A. (2020). Análise da origem dos gols de uma equipe de futsal marcados em jogos como visitante e mandante. Revista Brasileira de Futsal e Futebol. 12 (51), 720-725.

Santana, W. C. \& Vacario, E. A. (2012). Analysis of fouls with hurdles in high lever female futsal. Pensar Prática. 15 (3), $551-820$.

Santos, J., Mendez-Domínguez, C., Nunes, C., Gómez, M. A. \& Travassos, B. (2019). Examining the key performance indicators of all-star players and winning teams in elite futsal. International Journal of Performance Analysis in Sport. 20 (1), 78-89.

Sarmento, H., Clemente, F. M., Araújo, D., Davids, K., McRobert, A. \& Figueiredo. (2018). What performance analysts need to know about research trends in association football (2012-2016): a systematic review. Sports Medicine. 48, 799-836.

Sarmento, H., Marcelino, R., Anguera, M. T., Campaniço, J. Matos, N. \& Leitão, J. C. (2014). Match analysis in football: a systematic review. Journal of Sports Sciences. 32 (20), 1831-1843. https://doi.org/10.1080/02640414.2014.898852

Sarmento, H., Bradley, P., Anguera, M. T., Polido, T., Resende, R. \& Campaniço, J. (2016). Quantifying the offensive sequences that result in goals in elite futsal matches. Journal of Sports Science. 34 (7), 621-9. https://doi.org/10.1080/02640414.2015.1066024

Schneider, I., Voser, R. C. \& Voser, P. E. G. (2015). Análise de gols sofridos e gols feitos pela equipe de futsal de Nova Itaberaba-SC categoria sub-17 no campeonato catarinense 2013/2014. Revista Brasileira de Futsal e Futebol. 7 (25), 327-331.

Silva, A. S., Oliveira, J. J., Rosa Junior, N. A. \& Vilela Ribeiro, A. G. (2018). Indicadores técnicos das equipes vencedoras e perdedoras da Liga dos Campeões 2014/2015. Revista Brasileira de Futsal e Futebol. 10 (37), 179-185.

Silva, D. M. B., Miranda, B. L.G., Caldas, E. S., Ferreira, B. R. S., Silva, N. B., Marques, R. F. \& Araújo, M. L. (2019). Análise das ações defensivas das goleiras durantes competições de Futsal feminino. Revista Brasileira de Futsal e Futebol. 11 (44), 319-323.

Souza, C. E. S., Nozaki, J. M., Leitão, A. \& Martins, M. Z. (2019). Goleiro-Linha e Linha-Goleiro: diferentes usos estratégico-táticos do goleiro na liga nacional de Futsal de 2016. Revista Brasileira de Futsal e Futebol. 10 (41), 655-662.

Souza, P. R. C., Ribeiro, R. M. R., Rocha, R. R. M., Fernandes, B. M. \& Moreira, R. C. (2013). Análise das finalizações como indicadores de rendimento em jogos de futsal. Revista Mackenzie de Educação Física e Esporte. 12 (2), 89-99.

Szwarc1, A. \& Oszmaniec, M. (2020). A model of the efficiency of goalkeepers' actions in futsal. Human Moviment. 21 (4), 44-53. https://doi.org/10.5114/hm.2020.95990

Travassos, B., Duarte, R., Vilar, L., Davids, K. \& Araújo, D. (2012). Practice task design in team sports: representativeness enhanced by increasing opportunities for action. Journal of Sports Sciences. 30 (13), 1447-54. https://doi.org/10.1080/02640414.2012.712716

Travassos, B., Bourbousson, J., Esteves, P. T., Marcelino, R.; Pacheco, M. \& Davids, K. (2016). Adaptive behaviours of attacking futsal teams to oppositiondefensive formations. Human Movement Science. 47, 98-105. http://dx.doi.org/10.1016/j.humov.2016.02.004

Ueda, L. S. C., Menegassi, V. M., Avelar, A., Rechenchosky, L., Silva, F. L. O. \& Borges, P. H. (2020). Analysis of the execution of core tactical principles and technical efficiency of primary school futsal players. Revista Brasileira de Cineantropometria \& Desempenho Humano. 22 , e65221. https://doi.org/10.1590/1980-0037.2020v22e65221

Vicente-Vila, P. \& Lago-Peñas, C. (2016). The goalkeeper influence on ball possession effectiveness in futsal. Journal of Human Kinetics. 2 (51), 217-224. https://dx.doi.org/10.1515\%2Fhukin-2015-0185

Vilar, L., Araújo, D., Davids, K., Correia, V. \& Esteves, P. T. (2013). Spatial-temporal constraints on decision-making during shooting performance in the team sport of futsal. Journal of Sports Science. 31 (8), 840-6. https://doi.org/10.1080/02640414.2012.753155

Vilar, L., Araújo, D., Davids, K., Travassos, B., Duarte, R. \& Parreira, J. (2014). Interpersonal coordination tendencies supporting the creation/prevention of goal scoring opportunities in futsal. European Journal of Sport Science. 14 (1), 28-35. https://doi.org/10.1080/17461391.2012.725103

Voser, R. C., Mares, J. C., Cardoso, M. S., Morales, P. S. \& Duarte Junior, M. A. (2018). The period of highest occurrence of goals in futsal: a study in school games. Revista Brasileira de Futsal e Futebol. 10 (38), 354.

Voser, R. C., Moraes, J. C., Cardoso, M. F. S., da Silva, P. M. \& Duarte Junior, M. A. (2018). O período de maior ocorrência de Gols no Futsal: um estudo em jogos escolares. Revista Brasileira de Futsal e Futebol. 10 (38), 354-358.

Voser, R. C., Voser, P. E. G. \& Silva, C. G. (2016). A origem dos Gols da Liga de Futsal 2014. Revista Brasileira de Futsal e Futebol. 8 (29), 155-160.

Voser, R. C., Cardoso, M. F. S., Moares, J. C., Cunha, G. S., Voser, P. E. G. \& Morais, M. L. (2017). A relação entre chutes em direção ao gol e o resultado final da Copa do Mundo de Futsal na Tailândia em 2012. Revista Brasileira de Futsal e Futebol. 9 (34), 258-256.

Whittemore, R. \& Knafl, K. (2005). The integrative review: updated methodology. Journal of Advanced Nursing. 52 (5), 546-53. https://doi.org/10.1111/j.1365-2648.2005.03621.x

Yiannaki, C., Barron, D. J., Collins, D. \& Carling, C. (2020). Match performance in a reference futsal team during an international tournament: implications for talent development in soccer. Biology of Sport. 37 (2), 147-156. https://doi.org/10.5114/biolsport.2020.93040 